\title{
Fat Metabolism in Higher Plants
}

\section{$\beta$-HYDROXYLATION OF FATTY ACIDS BY A SOLUBLE PREPARATION FROM MATURING AVOCADO MESOCARP}

\author{
By J. L. HARWOOD*, A. SODJA and P. K. STUMPF \\ Department of Biochemistry and Biophysics, University of California, \\ Davis, California 95616, U.S.A.
}

(Received 25 August 1972)

\begin{abstract}
1. An avocado supernatant fraction converted fatty acids of medium chain length $\left(\mathrm{C}_{8}-\mathrm{C}_{12}\right)$ into a polar product. 2 . The product was identified as the $\beta$-hydroxy derivative of the substrate by g.l.c. and t.l.c. analysis. 3. For hydroxylation of the fatty acids, CoA, ATP and molecular oxygen were required. Acyl carrier protein gave some stimulation. The reaction took place with oxygen alone if acyl-CoA was the substrate. 4. Hydroxylation was maximal with decanoic acid but dodecanoic acid and octanoic acid were also very active. Acids of shorter or longer chain lengths were not hydroxylated. 5. NAD ${ }^{+}$concentration caused complete inhibition at $0.5 \mathrm{~mm}$ and may be an important control mechanism for the reaction in vivo. 6. The reaction was inhibited by iodoacetamide and by bipyridyl and carbon monoxide, indicating involvement of thiol and heavy metal groups.
\end{abstract}

Fatty acid $\omega$-hydroxylation has been reported in the $10000 \mathrm{~g}$ supernatant from rat liver (Preiss \& Bloch, 1964) and in a solubilized microsomal preparation from rabbit liver (Lu \& Coon, 1968). The reaction is dependent on molecular oxygen and NADPH. Three components of the microsomes are also needed, one being haemoprotein P-450. In contrast, hydroxylation of fatty acids by Pseudomonas oleovorans (Peterson \& Coon, 1968), also in the $\omega$-position, utilizes NADH-rubredoxin reductase.

Two plant systems have been shown to hydroxylate fatty acids. The production of ricinoleic acids (12hydroxy, 18:1) from oleyl-CoA was reported in castor bean (Yamada \& Stumpf, 1964). In further investigations Galliard \& Stumpf (1966) showed that the enzyme was a mixed-function oxidase requiring molecular oxygen and NADH in addition to oleylCoA. Hydroxylation was stereospecific to yield the D-isomer. Walton \& Kolattukudy (1971), while studying cutin formation in leaves, observed hydroxylation of palmitic acid at the $\mathrm{C}-10$ and $\mathrm{C}-16$ positions before incorporation to cutin.

Preparations from the avocado mesocarp rapidly synthesize fatty acids from $\mathrm{C}_{2}$ precursors. Yang \& Stumpf (1965) first showed the incorporation of radioactivity from $\left[{ }^{14} \mathrm{C}\right]$ malonic acid and $\left[{ }^{14} \mathrm{C}\right]-$ malonyl-CoA into long-chain acids by the $15000 \mathrm{~g}$ supernatant. This synthetase contained a heat-stable component (Overath \& Stumpf, 1964) later isolated and identified as acyl carrier protein (Simoni et al.,

* Present address: Department of Biochemistry, University of Leeds, Leeds 2, U.K.
1967). While studying the synthesis of fatty acids by the soluble proteins we observed the rapid hydroxylation of medium-chain-length fatty acids. Some properties of the system are now reported.

\section{Experimental}

\section{Materials}

Plant material. Avocado mesocarp (Persea americana var. Fuerte) was homogenized in a Potter homogenizer and fractionated as described by Harwood \& Stumpf (1972). The $105000 \mathrm{~g} \times 60 \mathrm{~min}$ supernatant was used in all experiments. Safflower seeds (Carthamus tinctorius var. Hela), 20 days after flowering, were fractionated in a similar manner.

Spinach chloroplasts were isolated as described by Stumpf \& Boardman (1970). The intact chloroplasts were washed three times with $0.1 \mathrm{M}$-potassium phosphate, $\mathrm{pH} 7.5$, and spun at $1100 \mathrm{~g} \times 5 \mathrm{~min}$ to yield the lamellae. The purity of the lamellar preparation was checked with an antiserum to carboxydismutase.

Chemicals. Coenzyme A was obtained from Nutritional Biochemical Corp. (Des Plaines, Ill., U.S.A.), dodecanoic acid from Armour Chemical Division (Chicago, Illinois, U.S.A.), 5,5'-bipyridyl from Eastman Organic Chemicals (Rochester 3, N.Y., U.S.A.) and 1,12-dodecanedicarboxylic acid from Aldrich Chemical Co. Inc. (Milwaukee, Wis., U.S.A.). ATP, NADH, NADPH, NAD ${ }^{+}$, GSH and iodoacetamide were obtained from Sigma Chemical Co. (St. Louis, Mo., U.S.A.). Methyl $\beta$-hydroxydecanoate and methyl $\alpha$-decanoate were obtained 
from Analabs Inc. (New Haven, Conn., U.S.A.). Dimethylformamide was redistilled and stored over a molecular sieve. n-Butylboronic acid was obtained from Supelco, Bellefonte, Pa., U.S.A.

$\left[2-{ }^{14} \mathrm{C}\right]$ Malonic acid $(14.5 \mathrm{mCi} / \mathrm{mmol})$ and $\left[2-{ }^{14} \mathrm{C}\right]-$ malonyl-CoA $(20.6 \mathrm{mCi} / \mathrm{mmol})$ were obtained from New England Nuclear Corp. (Boston, Mass., U.S.A.). $\left[1-{ }^{14} \mathrm{C}\right]$ Heptanoic acid $(50 \mathrm{mCi} / \mathrm{mmol})$, sodium [1${ }^{14} \mathrm{C}$ ]octanoate $(2.5 \mathrm{mCi} / \mathrm{mmol})$, sodium $\left[1-{ }^{14} \mathrm{C}\right]$ decanoate $(4.2 \mathrm{mCi} / \mathrm{mmol}),\left[1-{ }^{14} \mathrm{C}\right]$ lauric acid $(21 \mathrm{mCi} /$ mmol), $\left[1-{ }^{14} \mathrm{C}\right]$ myristic acid $(15.4 \mathrm{mCi} / \mathrm{mmol}),\left[1-{ }^{14} \mathrm{C}\right]$ myristyl-CoA $(1 \mathrm{mCi} / \mathrm{mmol}),\left[1-{ }^{14} \mathrm{C}\right]$ palmitic acid $(55 \mathrm{mCi} / \mathrm{mmol}),\left[1-{ }^{14} \mathrm{C}\right] \mathrm{stearic}$ acid $(48.4 \mathrm{mCi} / \mathrm{mmol})$, sodium $\left[{ }^{14} \mathrm{C}\right]$ bicarbonate $(56.9 \mathrm{mCi} / \mathrm{mmol})$ and $\left[{ }^{3} \mathrm{H}\right]-$ $\mathrm{H}_{2} \mathrm{O}(25 \mathrm{mCi} / \mathrm{g})$ were obtained from New England Nuclear Corp.

Malonyl-CoA and acyl-carrier protein were prepared as previously described (Harwood \& Stumpf, 1971).

\section{Syntheses}

n-Butylboronate derivatives. The modified procedure of Brooks \& MacLean (1971) was employed. The reaction mixture contained the hydroxy acid and butylboronate in a ratio of $1: 2(w / w)$ in dimethylformamide $(200-400 \mu \mathrm{l})$ as the solvent. After 10-15 min at room temperature, a few drops of water were added, the product was extracted with diethyl ether and analysed by g.l.c. with $1 \% \mathrm{OV}-17$ on a $6.35 \mathrm{~mm} \times 1.52 \mathrm{~m} \mathrm{~S}$.S. column at $135^{\circ} \mathrm{C}$.

Menthylchloroformate derivatives. The procedure used was that of Annett \& Stumpf (1972).

\section{Methods}

Chemical oxidation of hydroxy fatty acids. The oxidizing solution contained $1 \mathrm{~g}$ of chromic trioxide, $3 \mathrm{ml}$ of water and $0.87 \mathrm{ml}$ of conc. $\mathrm{H}_{2} \mathrm{SO}_{4}$. The sample to be oxidized was taken up in $1 \mathrm{ml}$ of acetone and 1 drop of oxidizing solution added at $5^{\circ} \mathrm{C}$. After $30 \mathrm{~min}$ the sample was diluted four times with water and extracted into diethyl ether.

Determination of thioester and oxygen ester content of the reaction mixture. The method of Barron \& Mooney (1968) as detailed by Vijay \& Stumpf (1971) was used.

Enzyme hydroxylation system. The basic system used contained $30 \mathrm{~mm}$-potassium phosphate, $\mathrm{pH} 7.4$, $1 \mathrm{~mm}$-ATP, $0.2 \mathrm{~mm}-\mathrm{CoA}, 8 \mathrm{~mm}-\mathrm{GSH}, 10 \mu \mathrm{g}$ of acyl carrier protein (Escherichia coli) and $0.2 \mathrm{mM}-\left[{ }^{14} \mathrm{C}\right]-$ lauric acid $(2.5 \mu \mathrm{Ci} / \mu \mathrm{mol})$. Final volume was $1.0 \mathrm{ml}$ and $0.8-1.5 \mathrm{mg}$ of avocado supernatant protein was used. After incubation for $1-2 \mathrm{~h}$ at $25^{\circ} \mathrm{C}$ with air as the gas phase the reaction was terminated with $0.1 \mathrm{ml}$ of $5 \mathrm{M}-\mathrm{H}_{2} \mathrm{SO}_{4}$ and lipids were extracted and analysed as previously noted (Harwood \& Stumpf, 1971).
Chromatography. Thin-layer chromatography of the products was made with $7.5 \% \mathrm{AgNO}_{3}$-silica gel $G$ plates with hexane-diethyl ether $(9: 1, v / v)$. Silica gel $\mathrm{G}$ plates were also run with methanol-chloroform$\mathrm{HCl}$ (13:87:0.5, by vol.), light petroleum (b.p. 30$\left.60^{\circ} \mathrm{C}\right)$-diethyl ether $(50: 50, \mathrm{v} / \mathrm{v})$ and ether-benzeneethanol-acetic acid (40:50:2:0.2, by vol.). Extraction of the hydroxy acid from the plates was with chloroform-methanol $(2: 1, \mathrm{v} / \mathrm{v})$.

\section{Results and Discussion}

\section{Nature of the product}

When lauric acid was incubated with avocado supernatant under the standard conditions (see the Experimental section) over $50 \%$ of the substrate was converted into a much more polar product. The identification of this polar product as $\beta$-hydroxylauric acid was supported by the following evidence.

(1) As shown in Fig. 1, the methyl ester of the product co-chromatographed with methyl $\beta$-hydroxylaurate on g.l.c.

(2) The trimethylsilyl derivatives of the methyl ester co-chromatographed with the trimethylsilyl derivatives of authentic methyl $\beta$-hydroxylaurate on g.l.c. Therefore the polar product has a single hydroxyl group.

(3) The derivatives of (1) and (2) co-chromatographed with the appropriate standards on $\mathrm{AgNO}_{3}-$ silica gel G plates (Fig. 2), as free acids on silica gel $\mathbf{G}$ plates in methanol-chloroform- $\mathrm{HCl}$, and as methyl esters in hexane-diethyl ether and diethyl etherbenzene solvent systems (see the Experimental section).

(4) Hydroxylation at the $\alpha$-position was excluded by comparison with authentic methyl $\alpha$-hydroxylaurate both on t.l.c. and g.l.c. systems.

(5) To exclude $\omega$-hydroxy fatty acid formation, the product was oxidized with chromic acid at $5^{\circ} \mathrm{C}$. The oxidation product was extracted, converted into the methyl esters and chromatographed by g.l.c. with dimethyl 1,12-dodecanedicarboxylate. The radioactive peak co-chromatographed with methyl 3-oxolaurate (retention time $4 \mathrm{~min}$ ) whereas dimethyl 1,12dodecanedicarboxylate had a retention time of $22 \mathrm{~min}$. Thus $\omega$-hydroxylation was excluded. Although methyl esters of 3-, 7-, and 16-hydroxystearic acid gave comparable $R_{F}$ values on $\mathrm{AgNO}_{3}$-silica gel G t.l.c. plates (Mangold, 1969), O'Brien \& Rouser (1964) showed clearly that methyl $\beta$-hydroxypalmitate had a characteristic retention time by g.l.c. different from that of the other isomers. Thus results obtained with $\beta$-hydroxylauric acid by employing t.l.c. and g.l.c. techniques as well as degradation techniques would support our view that the enzymic product is indeed $\beta$-hydroxylauric acid. At present there is no information concerning the stereoisomeric property of the product. 


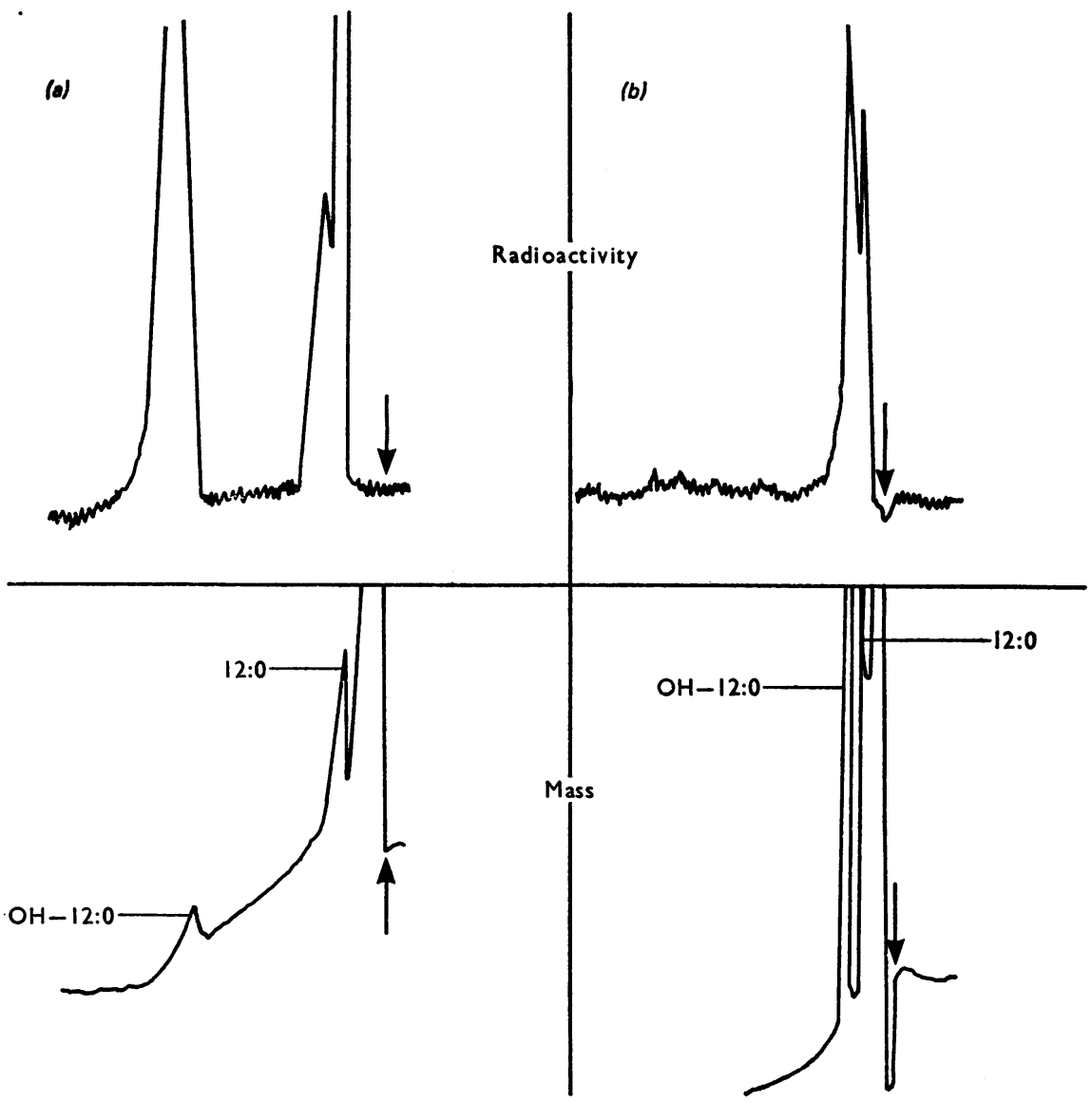

Fig. 1. Chromatography of the methyl esters of the reaction products from $\left[{ }^{14} \mathrm{C}\right]$ dodecanoate and authentic methyl DL-3-hydroxylaurate

Chromatography was by g.l.c. on: (a) $15 \% \mathrm{HI}-\mathrm{EFF} 2 \mathrm{BP}$ at $175^{\circ} \mathrm{C}$ as the methyl ester; (b) $15 \% \mathrm{HI}-\mathrm{EFF} 2 \mathrm{BP}$ at $165^{\circ} \mathrm{C}$ as the trimethylsilyl ether. For incubation conditions and extractions see the Experimental section.

(6) Only $\alpha$-hydroxy acids and $\beta$-hydroxy acids undergo rapid conversion at ambient temperature into the corresponding 1,3,2-dioxaborolan-4-one and 1,3,2-dioxaborinan-4-one derivatives respectively (Brooks \& MacLean, 1971). These derivatives can then be separated by g.l.c. techniques as described in the Experimental section. Cyclic $n$-butylboronate derivatives were made of the enzymic product as well as with authentic samples of $\beta$-hydroxy- and $\alpha$-hydroxydecanoic acid. With $\left[1-{ }^{14} \mathrm{C}\right]$ decanoic acid as the substrate, the cyclic boronate derivative co-chromatographed precisely with the derivative of $\beta$-hydroxydecanoic acid with a retention time of $14.9 \mathrm{~min}$. The $\alpha$-hydroxydecanoic derivative came off the column as a discrete peak with a retention time of $12.9 \mathrm{~min}$ and clearly did not migrate with the ${ }^{14} \mathrm{C}$-labelled derivative.

Menthylchloroformate derivatives are readily formed with $\alpha$-hydroxy acids but not with $\beta$-hydroxy acids (Annett \& Stumpf, 1972). All attempts to form derivatives of the enzymically formed product with this reagent were unsuccessful, as would be expected if the product was a $\beta$-hydroxy acid.

In addition, with $\left[1-{ }^{14} \mathrm{C}\right]$ decanoic acid as substrate the radioactive product and its derivatives cochromatographed with authentic $\beta$-hydroxydecanoate and its derivatives in the above systems. With all substrates a small unidentified peak was seen, which ran slightly slower than the substrate. This may be a mono-unsaturated derivative (see Fig. 2).

Vol. 130 


\section{Cofactor requirements}

Table 1 lists the cofactor requirements for the hydroxylation of decanoic acid and lauric acid. It can be seen that ATP and CoA are absolutely, and acylcarrier protein (either $E$. coli or avocado) partially, required for optimum activity. When the reaction vessel was flushed with nitrogen the hydroxylation was very much diminished, indicating the involvement of molecular oxygen. Although pyrogallol in alkaline solution was included in an inner well within the reaction vessel, presumably complete anaerobiosis was not achieved. Since ATP and CoA are required it is presumed that the acyl-CoA is the substrate, although because of the stimulation by acyl carrier protein there may be transfer of the acyl moiety to acyl-carrier protein before hydroxylation. However, when decanoyl-CoA was used as substrate, conversion into $\beta$-hydroxydecanoic acid occurred in the absence of CoA, ATP and acyl-carrier protein.

Possible formation of $\beta$-hydroxy acids via $\beta$-oxidation was tested by carrying out the incubation with cold lauric acid in the presence of $\left[{ }^{3} \mathrm{H}_{3} \mathrm{H}_{2} \mathrm{O}\right.$ and the complete $\beta$-oxidation cofactor components. If $\beta$ oxidation were taking place to any great extent then the enoyl hydratase step would include incorporation of ${ }^{3} \mathrm{H}$ into the $\beta$-hydroxy fatty acid. In the experiment $6.25 \mathrm{mCi}$ of $\left[{ }^{3} \mathrm{H}\right] \mathrm{H}_{2} \mathrm{O}$ was used, which would have allowed for incorporation of 90000 c.p.m. into $\beta$ hydroxylaurate at the rate of synthesis of the control. Less than 100 c.p.m. was observed, thereby excluding $\beta$-oxidation or hydration of an $\alpha \beta$-unsaturated acyl$\mathrm{CoA}$ as a possible method of formation. In addition, no loss of counts as volatile acetate was ever observed during incubation. Fatty acids of chain length greater than $\mathbf{C}_{12}$ would also be expected to be substrates if $\beta$-oxidation were the reaction mechanism (see below).

Table 2 shows the effect of addition of various nucleotides and thiol reagents to the incubation system. Addition of $\mathrm{NAD}^{+}$completely inhibited lauric acid hydroxylation at $0.5 \mathrm{~mm}$, and this may be an important control mechanism. NADH decreased the hydroxylation reaction somewhat, possibly because of its conversion into $\mathrm{NAD}^{+}$. NADP ${ }^{+}$ and NADPH had little effect. The inhibition by iodoacetamide and slight stimulation by GSH pointed to an involvement of thiol groups in the reaction. For the iodoacetamide experiment the extract was preincubated with inhibitor at $4^{\circ} \mathrm{C}$ and the reaction was initiated by adding the cofactor system and an excess of GSH to scavenge unchanged iodoacetamide. Several inhibitors of haemoproteins were also tested.

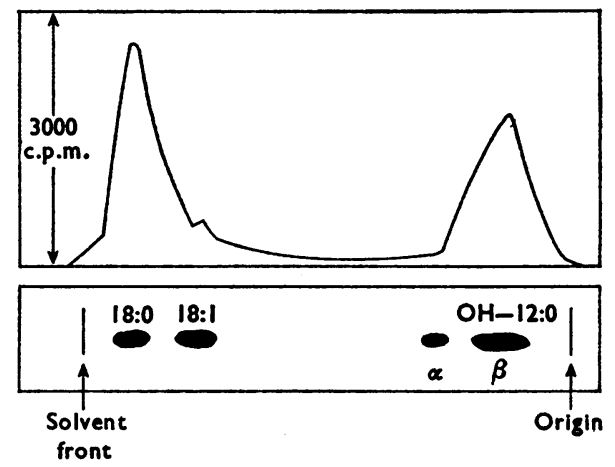

Fig. 2. Separation of the methyl esters of the reaction products from $\left[{ }^{14} \mathrm{C}\right]$ dodecanoic acid by t.l.c.

$7.5 \% \mathrm{AgNO}_{3}$-silica gel $\mathrm{G}$ plates were used with hexane-diethyl ether $(9: 1, v / v)$ as solvent. Non-radioactive methyl stearate and methyl oleate were used as typical markers for saturated and mono-unsaturated fatty acids since this t.l.c. system discriminates between classes of fatty acids but not chain length. Moreover, methyl $\alpha$-hydroxydodecanoate and methyl $\beta$-hydroxydodecanoate standards were included in the run.

\section{Table 1. Cofactor requirements for fatty acid hydroxylation}

See the Experimental section for basic incubation conditions. Results are mean values \pm S.D.

$\begin{array}{rlcc}\text { Substrate } & \text { Omission } & \begin{array}{c}\text { Hydroxylation } \\ \text { (pmol/min per mg of protein) }\end{array} & \% \text { of control } \\ {\left[1-{ }^{14} \mathrm{C}\right] \text { Decanoic acid }} & \text { None } & 860 \pm 127 & \\ & \text { Oxygen } & 485 \pm 52 & 51 \\ {\left[1-{ }^{14} \text { C]Lauric acid }\right.} & \text { None } & 1070 \pm 35 & 31 \\ & \text { Oxygen } & 336 \pm 213 & 14 \\ & \text { CoA } & 145 \pm 115 & 2 \\ & \text { ATP } & 19 \pm 19 & 25\end{array}$


Table 2. Effect of addition of pyridine nucleotides, thiol reagents or inhibitors to the incubation system

Basic assay conditions are given in the Experimental section but no GSH was used. Assay was with $\left[1-{ }^{14} \mathrm{C}\right]$ lauric acid substrate for $1 \mathrm{~h}$. Results are mean values \pm S.D.

\begin{tabular}{|c|c|c|}
\hline Addition & $\begin{array}{c}\text { Hydroxylation } \\
\text { (pmol/min per mg of protein) } \\
416 \pm 16\end{array}$ & $\%$ of control \\
\hline $0.5 \mathrm{mM}^{-\mathrm{NAD}}{ }^{+}$ & 0 & $\mathbf{0}$ \\
\hline $0.05 \mathrm{mM}^{-N A D^{+}}$ & $170 \pm 28$ & 41 \\
\hline $0.005 \mathrm{~mm}-\mathrm{NAD}^{+}$ & $270 \pm 54$ & 65 \\
\hline $0.5 \mathrm{~mm}-\mathrm{NADH}$ & $278 \pm 41$ & 67 \\
\hline 0.5 mM-NADP ${ }^{+}$ & $380 \pm 52$ & 92 \\
\hline $0.5 \mathrm{~mm}-\mathrm{NADPH}$ & $404 \pm 101$ & 98 \\
\hline $0.5 \mathrm{mM}-\mathrm{NADH}+0.5 \mathrm{~mm}-\mathrm{NADPH}$ & $150 \pm 18$ & 37 \\
\hline $8 \mathrm{mM}-\mathrm{GSH}$ & $1070 \pm 193$ & 264 \\
\hline None & $272 \pm 76$ & \\
\hline 1 mM-Iodoacetamide & $38 \pm 2$ & 14 \\
\hline Carbon monoxide & $98 \pm 19$ & 36 \\
\hline 1 mM-Cyanide & $247 \pm 24$ & 91 \\
\hline $1 \mu \mathrm{M}-5,5^{\prime}$-Bipyridyl & $87 \pm 41$ & 32 \\
\hline
\end{tabular}

Table 3. Ester content of reaction products

Incubation was with $\left[1-{ }^{14} \mathrm{C}\right]$ lauric acid substrate for $2 \mathrm{~h}$ under basic conditions (see the Experimental section). -S-, Sulphur ester; -O-, free acid.

\begin{tabular}{lcccc} 
& \multicolumn{4}{c}{ Ester content (\%) } \\
\cline { 2 - 5 } & $\mathrm{C}_{12: 0}$ & $\mathrm{C}_{12: 0}$ & $\beta-\mathrm{OH} \mathrm{C} \mathrm{C}_{12: 0}$ & $\beta-\mathrm{OH} \mathrm{C} \mathrm{C}_{12: 0}$ \\
Expt. 1 & $-\mathrm{S}-$ & $-\mathrm{O}-$ & $-\mathrm{S}-$ & $-\mathrm{O}-$ \\
Expt. 2 & 13 & 13 & 0 & 74 \\
& 29 & 8 & 0 & 63
\end{tabular}

Table 4. Chain-length specificity of hydroxylating system

Reaction conditions were as described in the Experimental section. Incubation was for $2 \mathrm{~h}$. Results are mean values \pm S.D.
Substrate

$\left[1-{ }^{14} \mathrm{C}\right]$ Butanoic acid

$\left[11^{14} \mathrm{C}\right]$ Heptanoic acid

$\left[1-^{14} \mathrm{C}\right]$ Octanoic acid

$\left[1-^{14} \mathrm{C}\right]$ Decanoic acid

$\left[1-^{14} \mathrm{C}\right]$ Dodecanoic acid

$\left[1-{ }^{14} \mathrm{C}\right]$ Tetradecanoic acid

$\left[1-{ }^{14} \mathrm{C}\right]$ Tetradecanoyl-CoA

$\left[1-{ }^{14} \mathrm{C}\right]$ Hexadecanoic acid

$\left[1-{ }^{14} \mathrm{C}\right]$ Octadecanoic acid

\begin{abstract}
Hydroxylation
(pmol/min per

$\mathrm{mg}$ of protein)
\end{abstract}

0

0

$694 \pm 74$

$968 \pm 12$

$847 \pm 8$

0

0

0

$\mathbf{0}$
5,5'-Bipyridyl at $1 \mu \mathrm{M}$, which forms complexes with heavy-metal ions (such as $\mathrm{Fe}^{2+}, \mathrm{Cu}^{2+}, \mathrm{Zn}^{2+}$ ), resulted $i^{n}$ strong inhibition, whereas $\mathrm{CN}^{-}$at $1 \mathrm{~mm}$ had Vol. 130 little effect. Since cyanide at this concentration can lead to non-specific secondary reactions the significance of this slight inhibition is not clear. Carbon monoxide with oxygen $(5: 1)$ inhibited hydroxylation by $64 \%$. These results indicate that a heavy-metal group may also be required for activity.

Estimation of the thioester and oxygen ester content of the acids at the end of incubation was carried out by reducing those fatty acids esterified with thiol groups to the corresponding alcohol with sodium borohydride (see the Experimental section). The results of this analysis are summarized in Table 3 and show that none of the $\beta$-hydroxylaurate product was present as the thioester. The substrate, lauric acid, on the other hand, was distributed $13 \%$ and $13 \%$ as a thioester and as a free acid respectively in one experiment and $29 \%$ and $8 \%$ in a second experiment. Thus if $\beta$-hydroxylauric acid is present as a thioester at the end of the reaction it is rapidly hydrolysed. The reaction product is the free acid, thereby decreasing the possibility of hydroxylation of fatty acid when esterified to phospholipid, such as has been suggested for desaturation in Chlorella (Gurr et al., 1969). 
Hydroxylation may occur at the thioester level, possibly on the acyl-(acyl-carrier protein) derivative, with subsequent hydrolysis to free acid (see Table 1).

The hydroxylation enzyme acted only on acids of medium chain length. As Table 4 shows, fatty acids of chain length greater than lauric acid did not react. Optimum activity was with decanoic acid but lauric acid and octanoic acid also gave significant activity. Since myristyl-CoA was not hydroxylated, this chainlength specificity could not be accounted for by the absence of a medium-chain-length acid-CoA ligase when free fatty acids were employed as the substrates.

The importance of this rapid hydroxylation reaction is not known at present. Safflower supernatant, which also synthesizes large amounts of fatty acids, has about one-tenth of the hydroxylation activity of avocado. We also tested the possible conversion of the hydroxy acids to longer-chain unsaturated acids in the presence of cofactors for fatty acid synthesis. No further metabolism of the $\beta$-hydroxy acids was observed whether they were continuously generated or added to various fatty acid synthetase systems, which included the safflower and avocado supernatants and spinach chloroplast. As the enzyme is soluble, further purification and study of the exact mechanism of hydroxylation can be easily undertaken.

Mrs. B. Clover provided technical assistance. J. L. H. was in receipt of a Wellcome Travel Grant. This work was supported in part by National Science Foundation Grant GB-19733X. The present paper is to be regarded as no. 52 of a series (paper no. 51: Harwood \& Stumpf, 1972).

\section{References}

Annett, R. \& Stumpf, P. K. (1972) Anal. Biochem. 47, 638-640

Barron, E. J. \& Mooney, L. A. (1968) Anal. Chem. 40, 1742-1744

Brooks, C. J. W. \& MacLean, I. (1971) J. Chromatogr. Sci. 9, 18-24

Galliard, T. \& Stumpf, P. K. (1966) J. Biol. Chem. 241, 5806-5812

Gurr, M. I., Robinson, M. P. \& James, A. T. (1969) Eur. J. Biochem. 9, 70-78

Harwood, J. L. \& Stumpf, P. K. (1971) Arch. Biochem. Biophys. 142, 281-291

Harwood, J. L. \& Stumpf, P. K. (1972) Arch. Biochem. Biophys. 148, 282-290

Lu, A. Y. H. \& Coon, M. J. (1968) J. Biol. Chem. 243, 1331-1332

Mangold, H. K. (1969) in Thin Layer Chromatography (Stahl, E., ed.), p. 387, Springer-Verlag Inc., New York

O’Brien, J. S. \& Rouser, G. (1964) Anal. Biochem. 7, 288-296

Overath, P. \& Stumpf, P. K. (1964) J. Biol. Chem. 239, 4103-4110

Peterson, J. A. \& Coon, M. J. (1968) J. Biol. Chem. 243, 329-334

Preiss, B. \& Bloch, K. (1964) J. Biol. Chem. 239, 85-88

Simoni, R.D., Criddle, R. S. \& Stumpf, P. K. (1967)J.Biol. Chem. 242, 573-581

Stumpf, P. K. \& Boardman, N. K. (1970) J. Biol. Chem. 245, 2579-2587

Vijay, I. K. \& Stumpf, P. K. (1971) J. Biol. Chem. 246, 2910-2917

Walton, T. J. \& Kolattukudy, P. E. (1971) Fed. Proc. Fed. Amer. Soc. Exp. Biol. 30, 1251

Yamada, M. \& Stumpf, P. K. (1964) Biochem. Biophys. Res. Commun. 14, 165-171

Yang, S. \& Stumpf, P. K. (1965) Biochim. Biophys. Acta 98, 19-26 